\title{
HIGH PERFORMANCES OF OXYFLUORIDE ELECTRODE USED IN LITHIUM ION BATTERY
}

\author{
K. GUERIN (1), N. LOUVAIN ${ }^{(1)}$, M. EL-GHOZZI ${ }^{(1)}$, C. CENAC-MORTHE $^{(2)}$ \\ (1) Clermont Université, Université Blaise Pascal, Institut de Chimie de Clermont-Ferrand, BP 10448, F-63000 \\ Clermont-Ferrand, France. Katia.araujo_da_silva@univ-bpclermont.Fr \\ (2) Centre National d'Etudes Spatiales, Toulouse, France,Email: Celine.Cenac-Morthe@cnes.fr
}

\begin{abstract}
Reactivity of pure molecular fluorine $F_{2}$ allows the creation of new materials with unique electrochemical properties. We demonstrate that titanium oxyfluoride $\mathrm{TiOF}_{2}$ can be obtained under molecular fluorine from anatase titanium oxide $\mathrm{TiO}_{2}$, while the fluorination of rutile $\mathrm{TiO}_{2}$ leads only to pure fluoride form $\mathrm{TiF}_{4}$. Contrary to most fluorides, $\mathrm{TiOF}_{2}$ is air-stable and hydrolyses poorly in humid conditions. Such stability makes it possible for $\mathrm{TiOF}_{2}$ to be studied as an electrode material in Li-ion secondary batteries systems. It shows capacities as high as $220 \mathrm{mAh} \mathrm{g}^{-1}$ and good cyclability at high current rates at an average potential of $2.3 \mathrm{~V}$ vs $\mathrm{Li}^{+} / \mathrm{Li}$. At such a potential, only $\mathrm{Li}^{+}$insertion occurs, as proven by in operando $\mathrm{XRD} /$ electrochemistry experiments.
\end{abstract}

\section{RESULTS AND DISCUSSION}

According to thermodynamics, the reaction of molecular fluorine $\mathrm{F}_{2}$ with rutile titanium dioxide $\mathrm{TiO}_{2}$ at $25{ }^{\circ} \mathrm{C}$ should lead to an equimolar mixture of $\mathrm{TiF}_{4}$ and $\mathrm{O}_{2}$ :

$\mathrm{TiO}_{2}(\mathrm{~s})+2 \mathrm{~F}_{2}(\mathrm{~g})=\mathrm{TiF}_{4}(\mathrm{~s})+\mathrm{O}_{2}(\mathrm{~g})$ (eq. 1$)$

From room temperature, the reaction is supposedly quantitative, with solid $\mathrm{TiF}_{4}$ formed. When the temperature increases, $\mathrm{TiF}_{4}$ starts to sublimate from approximately $200{ }^{\circ} \mathrm{C}$, and the presence of gaseous $\mathrm{TiF}_{4}$ becomes non-negligible above $250{ }^{\circ} \mathrm{C}$, which is lower than expected $\left(\mathrm{Tsub}=284^{\circ} \mathrm{C}\right)$.[1] The major difficulty is that only $\mathrm{TiF}_{4}$ is the only stable phase reported and no other, hypothetical or not, metastable fluoride or oxyfluoride phases can be included in the calculation. Moreover the difference of reactivity between anatase and rutile under molecular fluorine has never been analysed. In order to investigate the reactivity of titanium dioxide, anatase and rutile $\mathrm{TiO}_{2}$ powders have been fluorinated with a mixture of molecular fluorine and nitrogen gases at $250{ }^{\circ} \mathrm{C}$ for 18 hours in dedicated fluorination equipment.

Figure 1 displays the results of the in situ pressure data collected during the static fluorination process. First, let us consider the case of micrometre-sized powders of rutile and anatase $\mathrm{TiO}_{2}$. When rutile is heated up to $250^{\circ} \mathrm{C}$ in one atm. of a $\mathrm{F}_{2} / \mathrm{N}_{2}$ mixture, the pressure reaches about 1350 mbar. Then, when temperature is kept at $250{ }^{\circ} \mathrm{C}$, the pressure keeps on slowly increasing. This indicates the formation of a gaseous phase of $\mathrm{TiF}_{4}$ because of its high tensile strength at such temperature, in good accordance with thermodynamics. On the contrary, when anatase is fluorinated in similar conditions (Figure 1), the pressure profile obtained is clearly dissimilar, suggesting a different reactivity with pure fluorine between both polymorphs, contrary to what was expected. At $250{ }^{\circ} \mathrm{C}$, the pressure drastically decreases from 1350 to 1200 mbar, bespeaking the formation of a new solid phase with a net consumption of $F_{2}$ gas. All parameters being kept identical, the only reason for such difference is polymorphism.[2] The first interface encountered by $F_{2}$ gas is the crystal surface, thus crystal structure and morphology may affect the reactivity during a gas-solid process.[3] Indeed, such a difference between rutile and anatase is often discussed in adsorption of active species in photocatalysis.

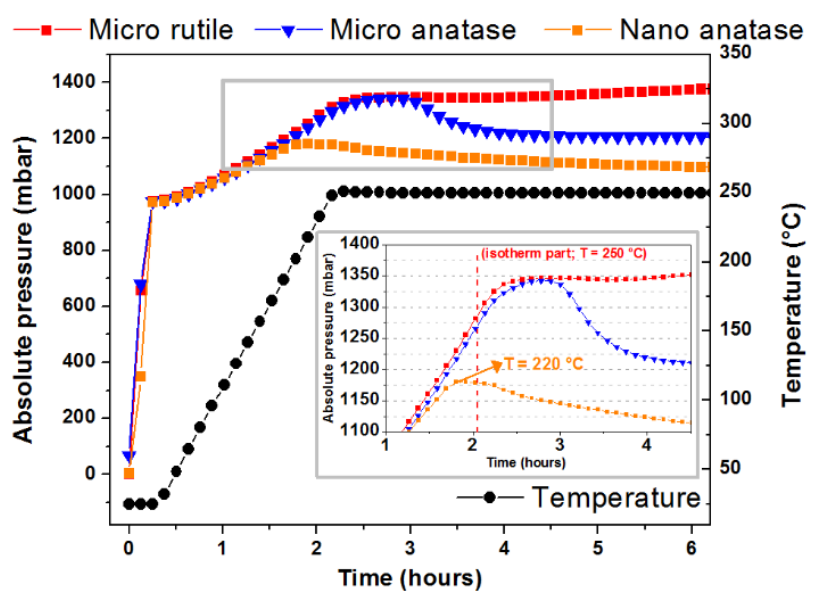

Figure 1. In situ total pressure data collected during static fluorination of rutile and anatase $\mathrm{TiO}_{2}$ with 1 atm. of a mixture of $\mathrm{N}_{2}$ and $\mathrm{F}_{2}$ gases at $250{ }^{\circ} \mathrm{C}$; the inset shows a zoom on the isotherm part of the curves.

Based on results from in situ pressure data, XRD and TG analyses, 30-nm nanocrystals of pure $\mathrm{TiOF}_{2}$ were 
obtained from a nanopowder of anatase $\mathrm{TiO}_{2}$.[4]
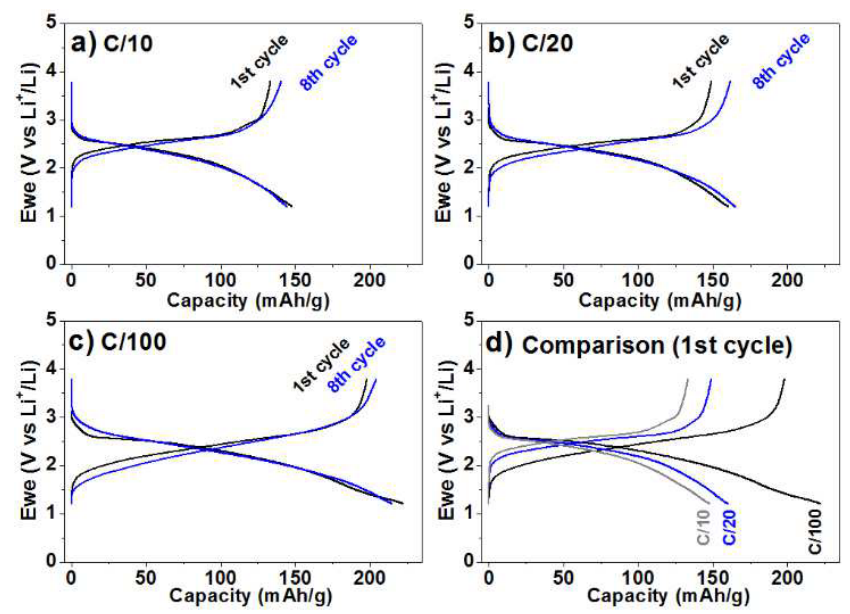

Figure 2. Galvanostatic voltage profiles for $\mathrm{TiOF}_{2} / \mathrm{Li}$ cells cycled at C/10 (a), C/20 (b), and C/100 (c) between 3.8 and $1.2 \mathrm{~V}$, and a comparison of their first cycle (d).

The as-prepared nanocrystals of $\mathrm{TiOF}_{2}$ were tested as electrode of Li-ion battery in Swagelok-type half-cells. The galvanostatic charge-discharge voltage profiles at three different current rates $(\mathrm{C} / 10, \mathrm{C} / 20$ and $\mathrm{C} / 100$, where $\mathrm{C}$ is set at $263.15 \mathrm{mAh} \mathrm{g}^{-1}$ for a 1-e- process) of the first and eighth cycles for $\mathrm{TiOF}_{2}$ versus Li between 3.8 and $1.2 \mathrm{~V}$ are shown in Figure 2. Such potential window as been chosen according to the studies by Chowdari et al. [5] showing that under $1.0 \mathrm{~V}$ no more potential plateau occurs in reduction. For each current density, the discharge curves show a relatively flat plateau around $2.25 \mathrm{~V}$ vs $\mathrm{Li}^{+} / \mathrm{Li}$. The $\mathrm{TiOF}_{2}$ nanocrystals electrode delivers a reversible specific capacity of $145 \mathrm{mAh} \mathrm{g}^{-1}$ at $\mathrm{C} / 10$ (Figure 2a) over the first eight cycles. The differences in shape and potential between the first cycle and the following ones are thus relatively small, indicating that the reaction mechanism is most probably the same. At slower rates (Figure 2bd), the reversible specific capacity is increased up to 155 $\mathrm{mAh} \mathrm{g}^{-1}(\mathrm{C} / 20)$ and an impressive $220 \mathrm{mAh} \mathrm{g}^{-1}(\mathrm{C} / 100)$. The fact that the specific capacity increases when reducing the current density would indicate a kinetically limited ionic or electrical diffusion mechanism, which could be explained either by the insulating nature of $\mathrm{TiOF}_{2}$, a common characteristic of fluorinated materials, or a none convenient volume/area ratio of the $\mathrm{TiOF}_{2}$ grains. Noteworthy, the potential of $\mathrm{TiOF}_{2}$ is $0.6 \mathrm{~V}$ higher than the one of anatase $\mathrm{TiO}_{2}$, as expected from the high electronegativity of the fluoride ion. We endeavoured to study the Li-insertion mechanism into $\mathrm{TiOF}_{2}$ in order to discriminate between a typical insertion, yielding a $\mathrm{Li}_{\mathrm{x}} \mathrm{TiOF}_{2}$ phase, and a conversion reaction, yielding a composite mixture of $\mathrm{LiF}$ and
LiyTiO2 (the formation of Ti0 in our working potential window has been ruled out). In a first step, an ex situ XRD study has been carried out on electrodes that were submitted to a $\mathrm{C} / 10$ rate and stopped at $2.5,2.0$, and 1.2 $\mathrm{V}$ during their first discharge. The impact of Liinsertion is relatively small on the XRD profile and no lithium fluoride can be detected, thus a priori indicating that no conversion reaction may occur in the chosen potential window.

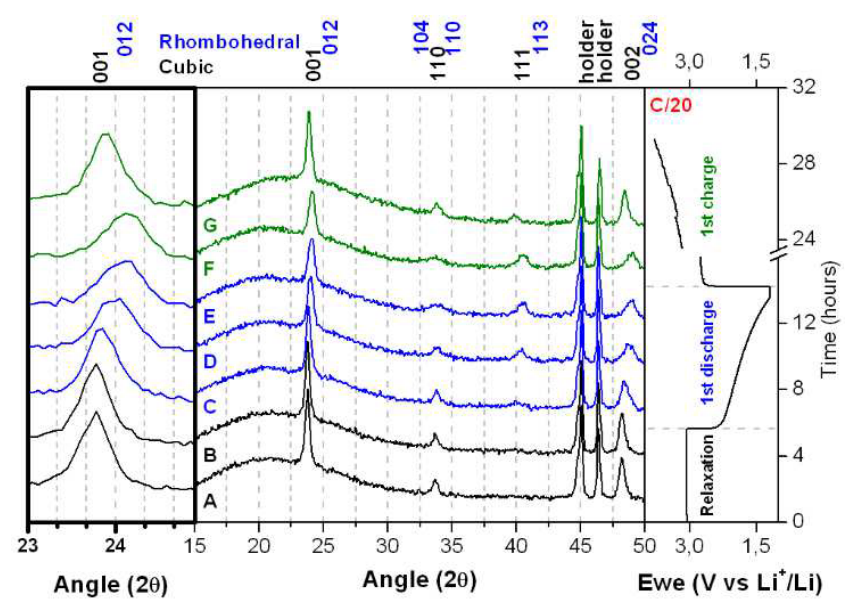

Figure 3. In operando evolution of the XRD pattern recorded at $\mathrm{C} / 20$ with a close view on the 001 reflection (left) and its corresponding voltage profile (right). Miller indices for the cubic (black) and rhombohedral (blue) cells are shown. Peaks between $45^{\circ}$ and $47.5^{\circ}$ are originating from the measurement cell.

In order to go further into details in the reaction mechanism of $\mathrm{TiOF}_{2}$ with $\mathrm{Li}$, and to probe cell parameters modulation, the first charge-discharge cycle was investigated by in operando XRD and the results are shown in Figure 3. During the open-circuit, only the well-defined peaks of crystalline cubic $\mathrm{TiOF}_{2}$ are visible in the diffraction pattern (Figure 3, patterns A and B) at $2 \theta=23.4^{\circ}, 33.3^{\circ}$, and $47.8^{\circ}$, corresponding to $(001)$, (011), and (002) hkl planes, respectively (ICSD \#160661), and no evolution, either in intensity or in position, can be detected. At the beginning of the reaction (Figure 3, pattern $\mathrm{C}$ ), the intensities of these peaks slightly decrease without observing any new peak in the diffraction pattern until half discharge, where Bragg peaks broaden and shift to higher angles (Figure 3 , pattern D). This is clearly noticeable on the close view on the 001 reflection (Figure 3). Please note that at this point of discharge a new peak is unambiguously appearing at $2 \theta=40.1^{\circ}$, and that such XRD behaviour is characteristic of Li-intercalation materials.[6] At the end of discharge (Figure 3, pattern E), the set of reflections of the initial cubic $\mathrm{TiOF}_{2}$ phase are broadened and 
shifted to higher angles, and their intensity is slightly lower. The angle shift may point to the cubic-torhombohedral phase transition described for chemically lithiated $\mathrm{TiOF}_{2},[7]$ and the hypothesis has been verified by a profile matching refinement of the fully discharged pattern using a rhombohedral model $(\mathrm{R}-3 \mathrm{c})$. All the diffraction features are well modelled by this phase with cell parameters $\mathrm{a}=5.206 \AA$ and $\mathrm{c}=13.334 \AA$, and this allows us to conclude that the phase at the end of the discharge is a lithiated $\mathrm{TiOF}_{2}$ of general formula $\mathrm{Li}_{\mathrm{x}} \mathrm{TiOF}_{2}$; thus, the present peaks at $2 \theta=23.8^{\circ}, 33.4^{\circ}$, $34.4^{\circ}, 40.1^{\circ}$, and $48.7^{\circ}$ would correspond to (012), (104), (110), (113), and (024) hkl planes, respectively. While at the early oxidation process the diffraction pattern can still be indexed by the rhombohedral cell (Figure 3, pattern F), the cubic non-lithiated $\mathrm{TiOF}_{2}$ phase is fully recovered at the end of charge (Figure 3, pattern G), therefore corroborating our hypothesis for Li-insertion and confirming the reversibility of the electrochemical performances obtained. With a concrete picture of the reactions of lithium with titanium oxyfluoride, it is now possible to deduce the lithium content, i.e. $x$ in $\mathrm{Li}_{x} \mathrm{TiOF}_{2}$ formula, from our electrochemical measurements. At a $\mathrm{C} / 10$ rate, a specific capacity of $145 \mathrm{mAh} \mathrm{g}^{-1}$ was obtained (Figure $2 \mathrm{a}$ ) and this leads to a lithiated $\mathrm{Li}_{\mathrm{x}} \mathrm{TiOF}_{2}$ with $\mathrm{x}=0.55$ (with a theoretical capacity of $263.15 \mathrm{mAh} \mathrm{g}^{-1}$ for 1 lithium); the lithium content can be as high as $\mathrm{x}=0.87$ at $\mathrm{C} / 100$, for a specific capacity equal to $220 \mathrm{mAh} \mathrm{g}^{-1}$ (Figure 2c).

The Li-insertion mechanism being validated, the cycling performances of our $\mathrm{TiOF}_{2}$ nanocrystals were investigated (Figure 4). The galvanostatic chargedischarge composition-voltage profiles of key cycles of a $\mathrm{TiOF}_{2} / \mathrm{Li}$ cell consecutively cycled at $\mathrm{C} / 20, \mathrm{C} / 10$, $\mathrm{C} / 20, \mathrm{C}$, and finally $\mathrm{C} / 20$ between 3.8 and $1.2 \mathrm{~V}$ are displayed in Figure $4 \mathrm{a}$. The most striking feature of this material is that the specific capacity obtained at $\mathrm{C} / 20$ is systematically resumed after being cycled at higher $\mathrm{C} / 10$ and $\mathrm{C}$ rates. In addition to its excellent cyclic capacity retention at sequential current rates, $\mathrm{TiOF}_{2} / \mathrm{Li}$ cells demonstrate a stable specific capacity at the high current density of $\mathrm{C}$ for more than 30 charge/discharge cycles between 3.0 and $1.2 \mathrm{~V}$ (Figure $4 \mathrm{~b}$ ). The discharge capacity slowly increases during the first thirty cycles and reaches $60 \mathrm{mAh} \mathrm{g}^{-1}$. This relatively high capacity retention at $\mathrm{C}$ may stem from the presence of $\mathrm{O}^{2-}$ ion in $\mathrm{TiOF}_{2}$, which makes it a semiconductor with a band-gap of approximately $2.5 \mathrm{eV}$,[8] whereas metal fluorides are commonly referred to as insulator with band-gaps larger than $4 \mathrm{eV}$ that cannot be cycled at such high density current without nanocarbon grafting.[9-11] An impressive capacity of $200 \mathrm{mAh} \mathrm{g} \mathrm{g}^{-1}$, close to the theoretical one, can even be obtained when the half-cell is cycled at $\mathrm{C} / 100$ (Figure $4 \mathrm{~b}$ ). The system retains a high capacity of $180 \mathrm{mAh} \mathrm{g}^{-1}$ after tenth of cycles, a value that can surely be improved by optimizing the battery engineering.

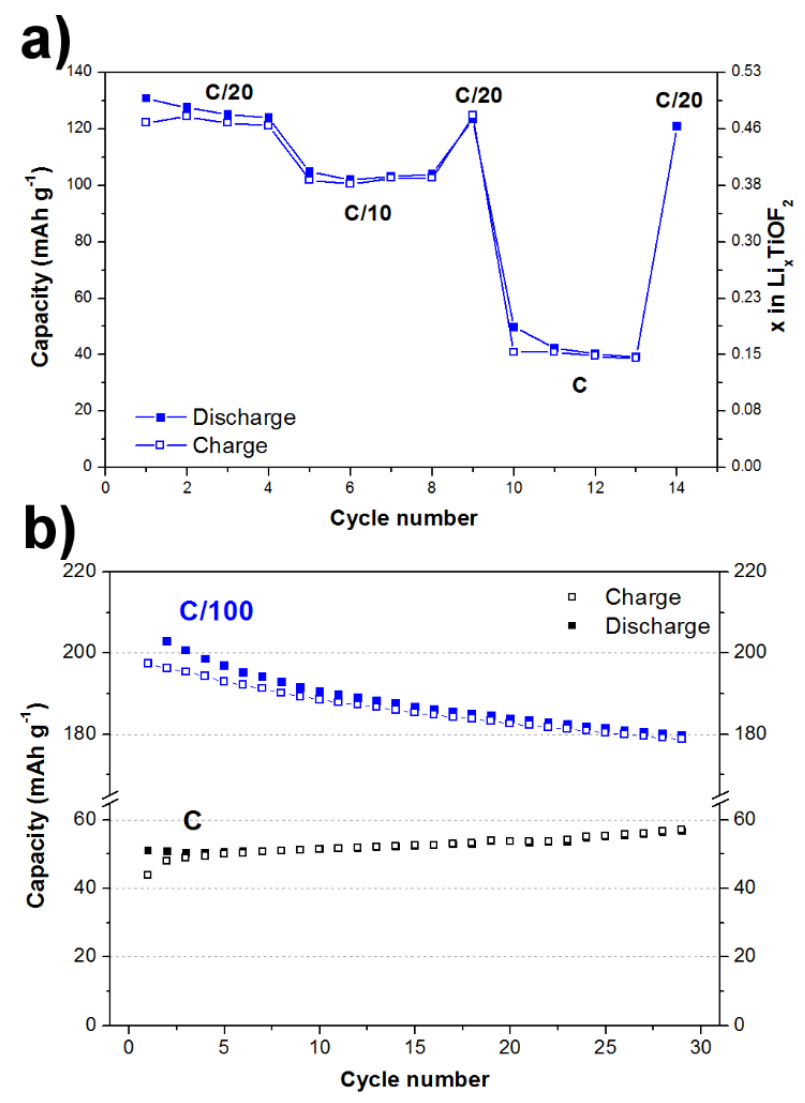

Figure 4. Composition-voltage profiles for one $\mathrm{TiOF}_{2} / \mathrm{Li}$ cell cycled at $\mathrm{C} / 20, \mathrm{C} / 10, \mathrm{C} / 20, \mathrm{C}$ and $\mathrm{C} / 20$ consecutively between 3.8 and $1.2 \mathrm{~V}$ (a); cycling performance curves of $\mathrm{TiOF}_{2}$ nanocrystals at current

\section{REFERENCES}

1. G. Brauer and G. Brauer, Handbook of Preparative Inorganic Chemistry, Academic Press, Inc., 1963.

2. D. S. Torkhov, P. E. Meskin, Y. V. Kolen'ko, V. A. Ketsko, A. A. Burukhin, B. R. Churagulov and N. N. Oleinikov, Dokl. Chem., 2004, 394, 36-38.

3. S. C. Li and U. Diebold, J. Am. Chem. Soc., 2010, 132, 64-66.

4. N. Louvain, Z. Karkar, M. El-Ghozzi, P. Bonnet, K. Guérin, P. Willman, J Mater. Chem A, 2014, 2, 15308-15315

5. M. V. Reddy, S. Madhavi, G. V. Subba Rao and B. V. R. Chowdari, J. Power Sources, 2006, 162, 13121321.

6. J. N. Reimers and J. R. Dahn, J. Electrochem. Soc., 1992, 139, 2091-2097.

7. D. W. Murphy, M. Greenblatt, R. J. Cava and S. M. Zahurak, Solid State Ionics, 1981, 5, 327-330. 
8. C. Xue, T. Narushima and T. Yonezawa, J. Inorg. Organomet. Polym., 2012, 23, 239-242.

9. R. Ma, Y. Dong, L. Xi, S. Yang, Z. Lu and C. Chung, ACS Appl. Mater. Interfaces, 2013, 5, 892-897.

10. C. Li, L. Gu, J. Tong and J. Maier, ACS Nano, 2011, 5, 2930-2938.

11. S. W. Kim, D. H. Seo, H. Gwon, J. Kim and K. Kang, Adv. Mater., 2010, 22, 5260-5264. 